\title{
Climate Global Change on Reproduction and Diversity of Agricultural Plants in Semi-Arid Regions of Georgia (Caucasus Ecoregion)
}

\author{
Maia Akhalkatsi* \\ Department of Plant Genetic Resources, Ilia State University, Georgia
}

Submission: January 31, 2017; Published: February 03, 2017

"Corresponding author: Maia Akhalkatsi, Head of Department of Plant Genetic Resources, Institute of Botany, Ilia State University, Faculty of Natural Sciences and Engineering, K Cholokashvili 3/5, 0162 Tbilisi, Georgia, Email: maia_akhalkatsi@iliauni.edu.ge

\section{Editorial}

The centre of evolution of plant varieties is in the Caucasus has been for many unique life forms and is a natural museum for rich genetic resources, much of which has been lost of certain species of agrarian plants for trade and local use. A number of threats emanate from the over exploitation of natural resources for fuel, fodder, manure, grazing and collecting of ornamental and edible plants. Human society is highly dependent on genetic resources of plant varieties, including those from wild and semi-domesticated sources, for the productivity of its agriculture. Biodiversity is present in all systems, including urban systems, and it plays a significant role everywhere. Thus, biodiversity concerns should be present in the management of all places, and more particularly so in those where human interventions are more severe. Currently, leading agricultural plants centres of the world, such as at USDA and FAO have big interest to collect germplasm and use it for agricultural plants [1]. The material, which will be studied have both high conservation value and at the same time are characterized by diseases of resistance. This determines high value of these agricultural plants to use them in plant food. Special emphases should be made that we will provide as well complete information and technology on seed propagation peculiarities of studied plants.

Climate change of anthropogenic origin is predicted to lead to mass extinction of plant and animal species in most regions of the world, and thus become one of the greatest threats to biodiversity [2]. If current projections of climate warming are accurate, future global change will include the disappearance of a significant portion of the Earth's biodiversity during the 21st century. Climate change will continue: The recent IPCC (Intergovernmental Panel on Climate change) report [3] states that climate warming is related to human activities and that warming will be more rapid than expected - with dramatic consequences on the earth's environment and the human population. The balance of evidence suggests a discernible human influence on the global climate [4]. Predictions of atmospheric warming of 1.4 to $5.8 \mathrm{~K}$ over the period 1990-2100 [4] may drastically alter existing biosphere patterns. The ecological effects of anthropogenic global climate change are of increasing concern for understanding and predicting climate driven vegetation change. Global circulation models exist that predict future climates and changes in coarse scale vegetation patterns. However, the efficacy of these models is limited by temporal and spatial scale problems and a poor understanding of how climate variation and human land use changes influence disturbance regimes and subsequent vegetation patterns.

Agricultural plant species survival is almost completely depended on species propagation by seeds. In arid and semiarid ecosystems there is a strong dependence of the rates of seed production and seedling establishment on the soil water content. Conditions of limited soil water availability in drought years lead plant into a state of water stress, which, causes limitation in seed productivity and quality and, if prolonged, is responsible for loss of turgidity, wilting and death of plants. While adult plant is better adapted to water limitation due to the deep root system able to uptake ground water, soil water content more sever affect has on germinating seeds, due to the direct or indirect dependence of the processes on the soil moisture conditions. Seedlings of many species of arid habitats have difficulty becoming established due to the aridity of the environment, which leads to high levels of competition among the existing vegetation and emerging seedlings for the limited water resources. On the other hand, anomalously high precipitation, occurred in some years, may allow rapid plant varieties growth and increased stand densities, resulting in potentially greater intraspecific competition for drought-limited water and greater susceptibility to drought, beetle infestation, and associated pathogens.

The reproductive phenology is the most sensitive phenomenon to the climate change. Investigation of drought effect on the duration 
of phenological stages in garden legume Trigonella caerulea (L.) S [5]. Has shown that the total duration of the reproductive period (i.e. time from appearance of the first flower until maturation of the last fruit) was approximately similar for all treatments. But, the duration of separate phenological phases varied among treatments. Drought-exposed plants had the longest period of seed formation and shorter periods of seed filling and maturation. The shortening of the seed filling period leads to the reduction of the final seed dry mass. Limitation in water availability at the terminal stage of seed development, during maturation drying, may affect loss of moisture from the seeds and reduce their quality, which in consequence will be expressed in lower germination ability. This difference had effect on germination percentage of seeds of drought exposed plants, which was low. It is expected in the current experiment that the differences in separate phenological stages will influence seed quality and their germination ability.

Water, among other environmental physical factors, plays an important role in the initiation of seed germination and seedling development. The uptake of water by seeds is the initial step to germination and is conditioned by the difference in water potentials between seed and soil. The establishment of a seedling to the definite site can be restricted by substrate water potential to which germination is sensitive to water availability. The time for germination of T. coerulea seeds has been considerably prolonged already at substrate water potential - $0.5 \mathrm{MPa}$, when compared to control seeds germinated in water [6]. The slowing affects not only radicle emergence, but as well the seedling growth. For seedling establishment in the field these changes might be dramatically enough, as a short radicle will be affected by water stress during rapid drying of the soil surface. We will test in the laboratory conditions requirement of studied species on substrate water potential and determine threshold values necessary for germination success. This will allow predicting species survival chances under changing soil moisture.

Most arid regions in Georgia -Iori Plateau, semi desert biomes of Shida and Lower Kartli, xerophytic habitats in Meskheti etc., are water-limited ecosystems [7]. Therefore small changes in precipitation amount or season may affect biological components that maintain nutrient and water cycles and energy flow through these ecosystems. In order to model the influence of climatic change on the plant reproduction and water supply in these ecosystems, it is important to simulate the natural balance that exists between water limitations and species propagation. Furthermore, although arid and semi-arid lands cover approximately one third of the earth's surface, few experimental warming studies have been conducted in these systems. This study might be considered as significant contribution in solving of such an important problem.

Species survival in arid and semi-arid ecosystems is highly dependent on annual climatic fluctuations and especially on precipitation that determine the temporal and spatial availability of soil water. In semi-arid and arid ecosystems, rain is the most important environmental parameter governing crucial life history processes in woody plants. Hence, climate change related shifts in precipitation pattern will potentially have severe consequences for woody plant population dynamics. In arid areas, recent climatologic studies proposed either a decrease in mean precipitation of 5-15\% by the year 2050 [3,4], or an increase by up to $30-40 \%$. Further studies suggest an increase in the frequency and variability of extreme rainfall events, as well as alternating phases with low and high rainfall. The large divergence between the various precipitation scenarios raises the question how woody plants would react along this spectrum.

\section{References}

1. Walther GR, Post E, Convey P, Menzel A, Parmesan C, et al. (2002) Ecological responses to recent climate change. Nature 416: 389-395.

2. Root TL, Price JT, Hall KR, Schneider SH, Rosenzweigk C, et al. (2003) Fingerprints of global warming on wild animals and plants. Nature 421: $57-60$.

3. McCarthy JJ, Canziani OF, Leary NA, Dokken DJ, White KS (2001) Climate change 2001: impacts, adaptation, and vulnerability. Intergovernmental Panel on Climate Change Working group II, Cambridge University Press, India, p. 1-10.

4. Houghton JT, Ding Y, Griggs DJ, Nouger M, van der Linden PJ, et al. (2001) Climate change 2001: The scientific basis. Intergovernmental Panel on Climate Change, Working group I. Cambridge University Press, India.

5. Akhalkatsi M, Losch R (2005) Water limitation effect on seed development and germination in Trigonella caerulea (Fabaceae). Flora 200(6): 493-501.

6. Akhalkatsi M, Lösch, Rainer (2001) Changes in water relations, solute leakage and growth characters during seed germination and seedling development in Trigonella caerulea (Fabaceae). Journal of Applied Botany and Food Quality 75(3-4): 144-151.

7. Nakhustrishvili G (2013) The Vegetation of Georgia. (South Caucasus). Berlin, Heidelberg, Springer-Verlag, Germany.

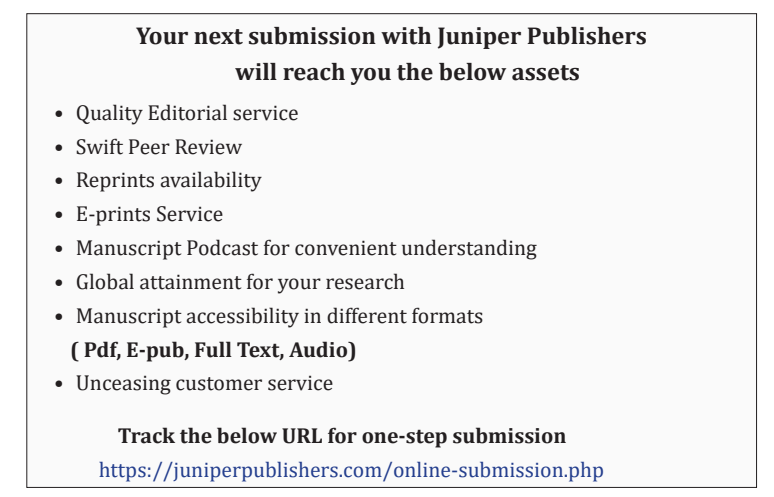

